\title{
BMJ Open Education as a strategy for managing occupational-related musculoskeletal pain: a scoping review
}

\author{
Thorvaldur Skuli Palsson (ib , ${ }^{1}$ Shellie Boudreau, ${ }^{2}$ Morten Høgh, ${ }^{1}$ \\ Pablo Herrero (1) , ${ }^{3}$ Pablo Bellosta-Lopez, ${ }^{4}$ Victor Domenech-Garcia, ${ }^{4}$ \\ Francesco Langella, ${ }^{5}$ Nicolo Gagni, ${ }^{5}$ Steffan Wittrup Christensen, ${ }^{1,6}$ \\ Morten Villumsen ${ }^{1,7}$
}

\section{To cite: Palsson TS, \\ Boudreau S, Høgh M, et al. Education as a strategy for managing occupational- related musculoskeletal pain: a scoping review. BMJ Open 2020;10:e032668. doi:10.1136/ bmjopen-2019-032668 \\ - Prepublication history and additional material for this paper are available online. To view these files, please visit the journal online (http://dx.doi org/10.1136/bmjopen-2019- 032668).}

Received 02 July 2019 Revised 11 December 2019 Accepted 10 January 2020
Check for updates

(c) Author(s) (or their employer(s)) 2020. Re-use permitted under CC BY-NC. No commercial re-use. See rights and permissions. Published by BMJ.

For numbered affiliations see end of article.

Correspondence to Dr Thorvaldur Skuli Palsson; tsp@hst.aau.dk

\section{ABSTRACT}

Background Musculoskeletal (MSK) pain is the primary contributor to disability worldwide. There is a growing consensus that MSK pain is a recurrent multifactorial condition underpinned by health and lifestyle factors. Studies suggest that education on work-related pain and individualised advice could be essential and effective for managing persistent MSK pain.

Objective The objective of this scoping review was to map the existing educational resources for work-related MSK (WRMSK) pain, and the effects of implementing educational strategies in the workplace on managing WRMSK pain.

Methods This scoping review assessed original studies that implemented and assessed education as a strategy to manage WMSK pain. Literature search strategies were developed using thesaurus headings (ie, MeSH and CINAHL headings) and free-text search including words related to MSK in an occupational setting. The search was carried out in PubMed, CINAHL, Cochrane Library and Web of Science in the period 12-14 February 2019.

Results A total of 19 peer-reviewed articles were included and the study design, aim and outcomes were summarised. Of the 19 peer-reviewed articles, 10 randomised controlled trial (RCT) studies assessed the influence of education on work-related MSK pain. Many studies provided a limited description of the education material and assessed/used different methods of delivery. A majority of studies concluded education positively influences work-related MSK pain. Further, some studies reported additive effects of physical activity or ergonomic adjustments.

Conclusions There is a gap in knowledge regarding the best content and delivery of education of material in the workplace. Although beneficial outcomes were reported, more RCT studies are required to determine the effects of education material as compared with other interventions, such as exercise or behavioural therapy.

\section{INTRODUCTION}

The socioeconomic impact of musculoskeletal (MSK) pain-related disability and associated work absenteeism affects the individual worker, the family, the worker's organisation and society. ${ }^{1-4}$ Efforts to prevent work-related

\section{Strengths and limitations of this study}

- The study design allowed for including literature from non-randomised studies to investigate the role of education for managing work-related musculoskeletal pain.

- The study presents a broad overview of resources available for healthcare professionals and the general public regarding work-related musculoskeletal pain.

- Relevant studies conducted in working populations may have been excluded if the article did not state that the focus was on work-related pain.

- The scoping review search strategy was not peer reviewed.

MSK (WMSK) pain by modifying the physical load seem inadequate ${ }^{56}$ and the lack of effects may pertain to the nature of MSK pain where, for example, psychological health and lifestyle-related factors play a significant role. ${ }^{278}$ Therefore, strategies for addressing WMSK pain require re-conceptualisation ${ }^{7910}$ and inclusion of multifactorial approaches. Ultimately, re-conceptualising the understanding of WMSK pain would imply an abandonment of a direct (causal) relation between work-related activities (eg, sitting, lifting and load) and WMSK pain. Instead, work-related activities should be considered one of many contributors to WMSK pain. ${ }^{4}$

By accounting for the multidimensional nature of WMSK pain and individual variability, a previous interventional study ${ }^{11}$ demonstrated a small but significant pain reduction where the level of pain relief was significantly associated with the number of clinician-worker interactions. A similar effect was observed on return to work when adopting a multidisciplinary approach including a brief two-session intervention with a healthcare professional. ${ }^{12}$ 


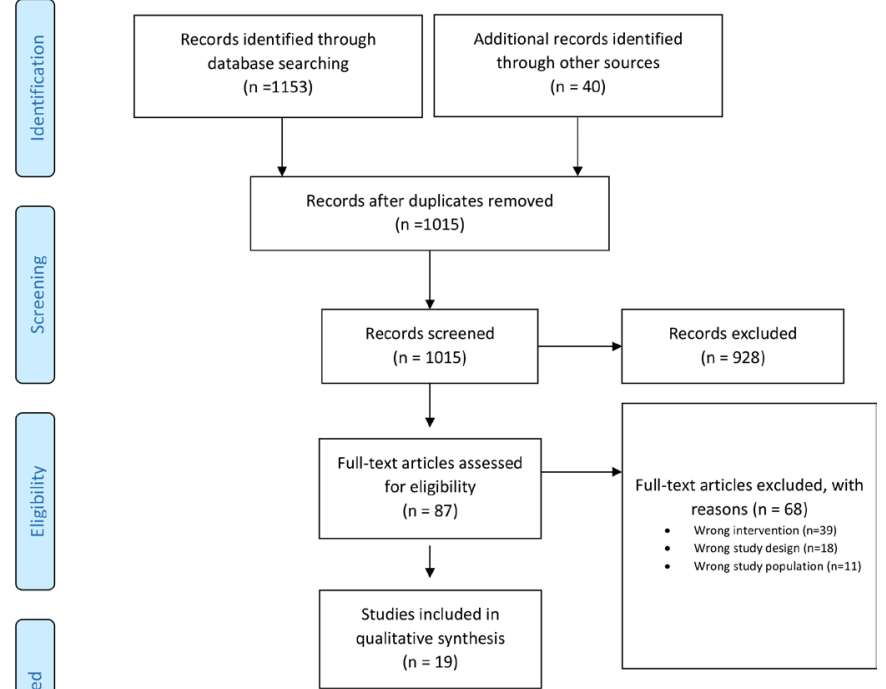

Figure 1 PRISMA flowchart demonstrating the findings in each step of the screening process.

From a socioeconomic perspective, enabling individuals return or continue to work despite having episodes of recurrent pain may be beneficial for the individual worker and the organisation. ${ }^{13}$ In this regard, organisations should adopt a broad approach, appreciating the multidimensional nature of pain for ensuring workability instead of solely focusing on prevention and management of WMSK pain. ${ }^{14}$ Successful rehabilitation of WMSK may depend on better collaboration and communication between the organisation, managers and the individual worker. $^{10}{ }^{15}$ Furthermore, communicating education about work-related pain and individualised advice could be essential for the management of persistent MSK pain. ${ }^{16-18}$ In fact, communication of non-threatening information about MSK pain may reduce absenteeism. ${ }^{19}{ }^{20}$ However, an overview of educational material for employees for the self-management of WMSK pain and implementation strategies for pain management within the workplace is lacking.

The objective of this scoping review was to map the existing educational resources focusing on WMSK pain. Moreover, the objective was to provide an overview of the available evidence on implementation of educational resources in occupational settings to help manage WMSK pain.

\section{METHODS}

\section{Study design and literature search strategies}

This scoping review included original studies that implemented and assessed education as a strategy to manage WMSK pain. A scoping review was chosen as a starting point to get a broad overview of any existing evidence in the field. The reporting of this scoping review follows the PRISMA-ScR guidelines. ${ }^{21}$
The literature search strategy was developed to consider population, concept and context, and educational strategies to manage WMSK pain in a working population. For the purpose of this scoping review, educational strategies were defined as an initiative designed to educate the employees with the aim of promoting occupational health in the workplace. In addition, management strategy was defined as a method aimed at preventing or reducing the burden of MSK pain in an occupational setting. Studies were included if the effect of education was assessed in any way (ie, as the primary intervention or control) and if they were (1) based on peer-reviewed research articles performed on adult humans (above 18 years), (2) had full text available in English, (3) were focused on occupational-related pain in a working population, and (4) described management strategies aimed at promoting retention or well-being in the workplace. A PRISMA diagram, divided into the categories identification, screening, eligibility and inclusion, was used to document and guide the screening process as recommended $^{22}$ (figure 1). After identification and removal of duplicates, studies were excluded in the screening process (title and abstract) if (1) no abstract was available, (2) they were not in English, or (3) if title and abstract indicated that the focus of the article was outside the scope of the review. When screening for eligibility (full text), articles were excluded if (1) the intervention was wrong (ie, non-educational), (2) the study design was wrong (eg, opinion papers or prevalence studies) or (3) if the study was conducted in a non-occupational context (eg, the educational intervention was not specifically aimed at a working population).

Literature search strategies were developed using thesaurus headings (ie, MeSH and CINAHL headings) and free-text search including words related to MSK in an occupational setting. The search was carried out in PubMed, CINAHL, Cochrane Library and Web of Science in the period 12-14 February 2019. According to the indexing in PubMed, the MeSH term "musculoskeletal pain" only covers the terms myalgia and pelvic girdle pain. Therefore, the MeSH terms "Neck pain", "Back pain" and "Shoulderpain" were added in the PubMed search, as these were the areas considered to be most frequently investigated and reported in relation to occupational-related MSK pain. ${ }^{23}$ For a detailed description of the search strategy in each database, see table 1 . No restrictions on publication year were applied in order to enable full mapping of the area. When all records had been identified using the selection criteria, the reference lists of the included studies were screened to identify additional relevant studies. All studies identified using the literature search strategies were uploaded to Mendeley (Mendeley Ltd, Elsevier, London 2019) which was used for reference management and removal of duplicates.

\section{Educational and information sources for employees}

Various educational resources regarding occupational health are available to the public in an online format, for example, the European Agency for Safety and Health at 
Table 1 Search strategy for all the included databases

\begin{tabular}{|c|c|c|c|}
\hline Source & Thesaurus headings/free-text search & Results & $\begin{array}{l}\text { Date of } \\
\text { search }\end{array}$ \\
\hline \multirow[t]{4}{*}{ PubMed } & Occupational health & 29074 & 14 Feb 2019 \\
\hline & Neck pain & 6264 & \\
\hline & Back pain & 35590 & \\
\hline & $\begin{array}{l}\text { (((((“Musculoskeletal Pain”(Mesh)) OR “Neck Pain”(Mesh)) OR “Back } \\
\text { Pain”(Mesh)) OR “Shoulder Pain”(Mesh))) AND “Occupational } \\
\text { Health"(Mesh) }\end{array}$ & 410 & \\
\hline CINAHL & Occupational health & 39950 & 11 Feb 2019 \\
\hline \multirow{3}{*}{ Cochrane database } & Musculoskeletal pain & 694 & \\
\hline & "Occupational health" AND "musculoskeletal pain" & 135 & \\
\hline & (“Occupational health” (Mesh)) AND (“musculoskeletal pain” (Mesh)) & 40 & \\
\hline Web of Science & "Occupational health" AND “musculoskeletal pain" & 155 & 12 Feb 2019 \\
\hline Total no of hits & & 1153 & \\
\hline
\end{tabular}

Work website (www.osha.europa.eu). Although the credibility of these resources cannot be evaluated in a scoping review, a mapping of such resources (grey literature) was performed to obtain a broad overview of available educational resources for employees regarding MSK pain and how to self-manage WMSK. For these purposes, a free-text Google search was conducted using search terms relating to MSK in the workplace. Only resources from public authorities and trade unions in Europe were included in the search.

\section{Study selection and synthesis of results}

The screening process consisted of two steps and an overview can be seen in figure 1 . In the first step, two investigators (TSP and SB) independently identified potentially eligible articles by screening the title and abstract. For calibration purposes, the two investigators compared their findings after screening the first 100 papers from the first database (PubMed). This was done to improve the interrater reliability in the screening process. In the second step, the same investigators reviewed a full-text version of the articles for eligibility. If consensus was not reached, a third member of the research group (MV) had the final vote.

In the first step, articles were considered potentially eligible if the effects of education in an occupational setting where MSK pain was specifically evaluated. Education focused on the employees' understanding or knowledge on how to prevent and/or manage MSK pain in an occupational setting.

The objective of this scoping review was to map existing evidence. With this study design in mind, no attempt was made to critically evaluate the methodology or the overall confidence in the results from the included articles as discussed by Arksey and O'Malley. ${ }^{24}$ To map the existing evidence, the study design, objectives, method of delivery and main findings from the eligible articles were summarised and tabulated (table 2). The goal the scoping review was to then provide an overview based on a qualitative synthesis covering the following three themes:

- The overall outcome of using education to manage occupational-related MSK pain.

- Potential influence of delivery method.

- The individual workers' subjective evaluation of the educational intervention for managing their occupational-related MSK pain.

The qualitative synthesis included a distinction between the mode of education delivery, which covered booklet/ pamphlet, electronic resources (landing page or website), face-to-face or a combination.

\section{Patient and public involvement}

For this scoping review, patients' priorities, experience and preferences were not involved in the design of the study, forming the aims, search strategies or data syntheses. Study findings will be disseminated on a publicly available platform (websites and on social media).

\section{RESULTS}

After duplicate removal, the search strategy revealed 1015 articles. As outlined in figure 1, after excluding articles that did not fulfil the inclusion criteria based on screening of title and abstract (screening), 87 articles were included for full-text screening (eligibility). Following full-text screening, additional 68 articles were 


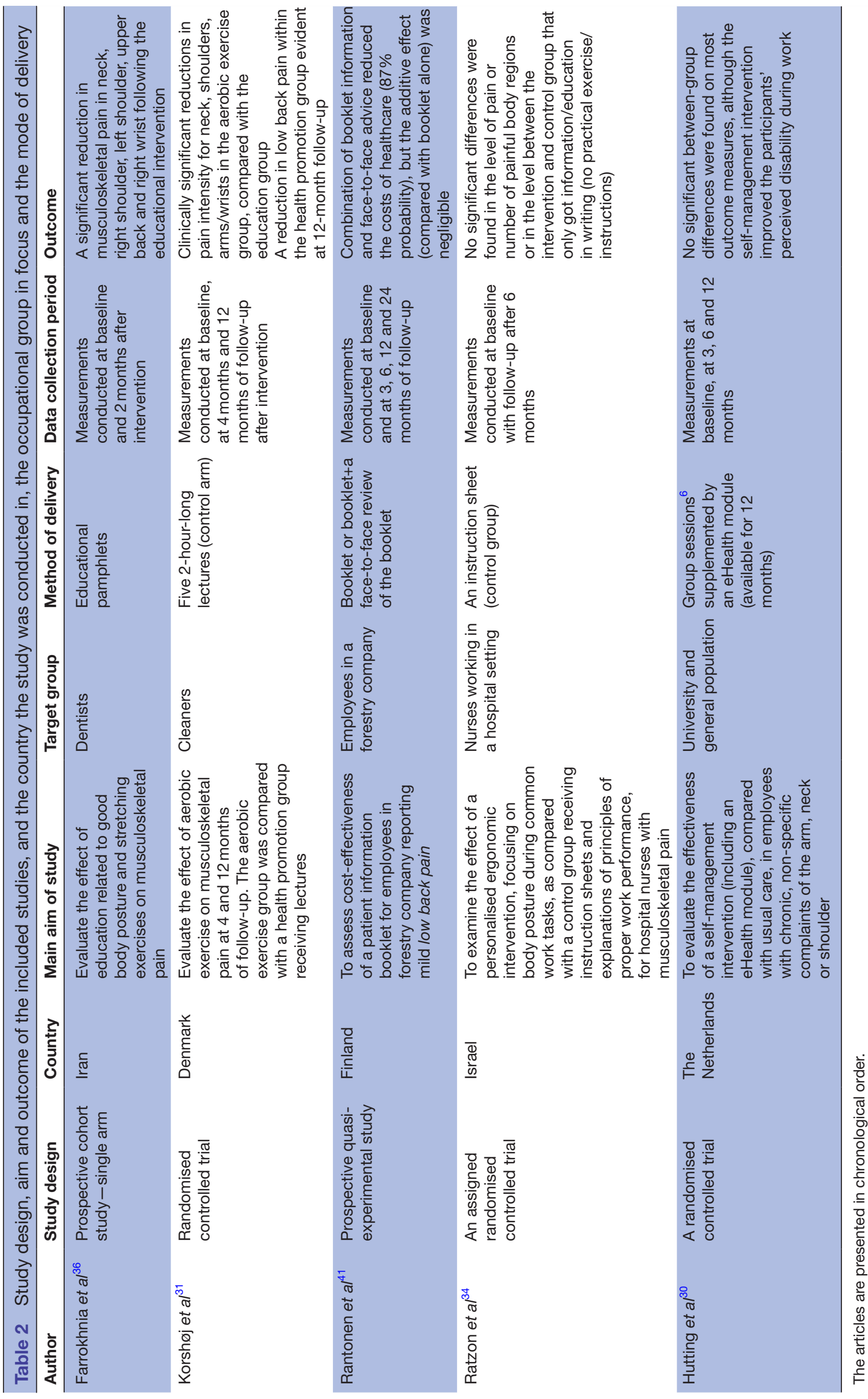


excluded, leaving 19 peer-reviewed articles for final inclusion (inclusion). The included studies are listed in table 2 where information regarding study design, aim of the study and outcomes of the three themes are presented. The two investigators (TSP and SB) had an agreement of $75 \%$ after screening title and abstract. Consensus was reached in the remaining $25 \%$ without the involvement of the third investigator.

\section{Characteristics of included studies}

Of the 19 studies included, 10 studies were randomised controlled trials. ${ }^{25-34}$ Eight studies used a prospective design where educational management strategies were tested using one ${ }^{35-39}$ or two groups. ${ }^{40-42}$ One study ${ }^{43}$ used a mixed-methods design to assess the individual workers' experience of the educational intervention. Further detail of the included studies can be found in table 2

\section{Synthesis of findings}

Components of education to manage occupational-related MSK pain

The content of the educational set-up and content varied between the included studies where three themes for methods of delivery emerged: written material in a hard copy (eg, pamphlet or book), ${ }^{25} 272932-34364143$ electronic delivery ${ }^{29} 3838$ or a teacher-student setting (eg, lecture or face-to-face teaching/mentoring) ${ }^{2526283135374042}$ Some of these included studies employed a mixed approach where education was supplemented by a more active approach (see Potential influence of delivery method section and table 2).

\section{Overall outcome of using education to manage occupational-} related MSK pain

The included studies were heterogeneous with regards to study design. Some studies lacked comparators ${ }^{35-39}$ and others focused on improving physiological parameters such as aerobic capacity ${ }^{28}{ }^{31}$ and strength. ${ }^{26}$ In general, a map of the existing evidence indicates that an educational intervention may positively influence musculoskeletal pain in the workplace, especially when including factors such as absence from work ${ }^{26} 29334041$ and cost-benefits of staying at work despite pain. ${ }^{37} 3941$ However, it needs to be acknowledged that favourable findings came from studies lacking a comparator. ${ }^{35-39}$ Also, in some of the studies, the educational arm was considered the control condition where the focus was on improving physiological parameters such as aerobic capacity ${ }^{2831}$ and strength ${ }^{26}$ suggesting that the power to detect significant changes in the educational arm might have been insufficient.

\section{Potential influence of delivery method}

It is unclear from the included studies whether adding more active components to the educational intervention with (ie, additional verbal education, exercise or multidisciplinary rehabilitation). In this regard, adding ergonomic advice or exercise was suggested to have additional benefits, ${ }^{25} 33$ although inconsistent findings were evident. ${ }^{27}$ For example, combining an educational booklet with face-to-face advice resulted in little or no additive effect on low back pain as assessed by pain levels, cost or absence from work. ${ }^{3241} \mathrm{~A}$ face-to-face intervention, however, may ensure better retention of the educational information as compared with electronic delivery, such as through email. ${ }^{43}$

\section{Individual workers' subjective evaluation of an educational intervention}

Three of the included studies ${ }^{30} 3943$ evaluated the subjective experience of participation in the study. Hutting et al investigated how six different online (eHealth) modules were received by the participants. ${ }^{30}$ Overall, this initiative was considered positive as it provided the participants with insight into their own condition and on how they could influence it themselves by implementing behaviour changes inside and outside the workplace. Behavioural change can be facilitated by the information in the provided material regarding, for example, ergonomics and exercise (at home and in the workplace). As a result, participants felt more confident in self-managing their pain condition. ${ }^{3943}$ In contrast to this, many workers may find it challenging to implement changes in their workplace as this might require unavailable resources (eg, office furniture and/or assistive equipment). ${ }^{43}$

\section{Educational and information sources for the general public}

A number of resources were found in several European countries (online supplementary appendix i). The search was confined to European countries. This was done to get an overview of the available resources in countries with a similar structure with regards to organisation of the occupational and healthcare sectors. The available material was presented in writing, infographics or video. All of these resources were unidirectional in the sense that they did not have any interactive features. The results from the literature search indicate an abundance of material. This material was available in generic and less often, occupational specific, for employees in several European languages.

\section{DISCUSSION}

This scoping review aimed at mapping the available educational initiatives for managing MSK pain at the workplace. The overall literature is heterogeneous and ranges between expert statements to randomised controlled trials. Therefore, the available literature does not allow for any conclusions on whether educational interventions are effective as a stand-alone management strategy for WMSK pain. Also, it is unclear whether the method of delivery is an important factor to consider and whether education needs to be combined with other interventions.

\section{Education as a means to manage WMSK pain}

It is clear from the literature presented in this scoping review (table 2) that education is deemed relevant for 
managing MSK pain at the workplace. However, one could argue that a relationship between attention given to the individual and the perceived outcome exists. Offering more services or options relevant to the job function and/or individual may have an additive effect on the outcome. ${ }^{3344}$

The availability of educational material also seems to matter, that is, that the employee feels that educational material can be accessed when needed. ${ }^{45}$ Also, it may be important that the intervention is directly related to the work functions of the employee in order to secure the relevance. ${ }^{46}$ When developing an eHealth educational module aimed at employees with MSK pain in the upper extremities and neck, Hutting et al demonstrated a need to address both generic and specific work functions. ${ }^{47}$ By using an eHealth module for such purposes, employees gained insight and awareness about their complaints which ultimately improved acceptance and coping strategies. ${ }^{45}$ The educational information therefore should aim broadly and include the aetiology of the pain experience, how emotional factors may play a role, how to deal with a high workload, considerations of available work capacity and the ability to set limits. The educational material should aim to improve the employee's knowledge of the work environment, including communication with colleagues and superiors, which may involve how to ask for help. ${ }^{43}$

Even though educational booklets may not be effective in preventing the onset of MSK pain, such as low back pain, benefits may emerge as promoting behavioural change, modifying health beliefs and improving attitudes. ${ }^{48}$ This is supported by information from one of the included articles, ${ }^{43}$ where the educational material was found to promote behavioural change, when the participants adopted a more active lifestyle at work and during leisure time. When weighing the effort against the potential gain, it is unsurprising that providing educational material was considered cost-effective. ${ }^{373941}$

To date, an abundance of educational material is available to the general public in several European languages outlining generic and some specific occupational cases (online supplementary appendix i). Much of this material, however, focuses on biomechanical aspects such as ergonomics rather than adopting a contemporary understanding of WMSK pain. Furthermore, it is unclear whether the material outlined from national registries or resources is based on scientific evidence, on expert opinions or a combination. Likewise, it is important that the employees are provided with information specific to their work tasks and role. Here, it seems important to acknowledge our understanding of health-related issues and technology is evolving, ${ }^{49}$ suggesting that educational material is constantly adapted to the latest evidence. Electronic platforms, containing eHealth modules ${ }^{30}$ would allow central updating without the need to replace hard copies as new evidence emerges.

\section{Methodological considerations and limitations}

This scoping review only included studies focusing on educational interventions for managing MSK pain in occupational settings. Therefore, the review did not include studies evaluating the benefit of such interventions in non-occupational settings. It is conceivable that excluded studies not performed in an occupational setting would have included working individuals. On the same note, the literature search was limited to English only, which inevitably might have excluded relevant information from scientific studies and other sources. In addition to this, the search for educational and information sources for employees was confined to European countries. This inevitably limited the number of educational resources in this review.

Subjecting the search strategy for peer review could add rigour to the search strategy. ${ }^{50}$ However, as an initial assessment in this area of scoping review, this was considered unnecessary. Nonetheless, future scoping reviews may benefit such a process.

It is important to illustrate that findings favouring an educational intervention mainly came from nonrandomised studies. ${ }^{36-39} 4243$ This may indicate that any intervention aimed at improving MSK pain in employees (in this case education) outperformed the option of doing nothing at all. A more active approach such as physical exercise 263133 or ergonomic advice ${ }^{25}$ seems to result in a slightly better outcome. However, educational interventions have the advantage of being cost-effective.

\section{CONCLUSION}

Some of the articles included in this scoping review suggest that educational resources can positively influence absenteeism and pain-related loss of workability. There is, however, a gap in knowledge regarding the best content and delivery of education of material in the workplace. Although beneficial outcomes were reported, more randomised controlled trial studies are required to determine the effects of education material as compared with other interventions, such as exercise or behavioural therapy.

\section{Author affiliations}

${ }^{1}$ Department of Health Science and Technology, Aalborg Universitet, Aalborg,

Denmark

${ }^{2}$ Aalborg University, Aalborg, Denmark

${ }^{3}$ Physiotherapy, San Jorge University, Zaragoza, Spain

${ }^{4}$ Department of Physiotherapy, Faculty of Health Sciences, University of San Jorge, Villanueva de Gallego, Aragón, Spain

${ }^{5}$ Orthopedic and Traumatology, IRCCS Istituto Ortopedico Galeazzi, Milano,

Lombardia, Italy

${ }^{6}$ Department of Physiotherapy, University College of Northern Denmark, Aalborg, Denmark

${ }^{7}$ Aalborg Municipality, Aalborg, Denmark

Twitter Thorvaldur Skuli Palsson @tspalsson, Shellie Boudreau @shellboudreau and Steffan Wittrup Christensen @SW_Christensen 
Collaborators Thorvaldur Skuli Palsson, Shellie A Boudreau, Morten Høgh, Pablo Herrero, Pablo Bellosta-López, Victor Domenech-Garcia, Fransceso Langella, Nicolò Gagni, Steffan Wittrup McPhee Christensen, Morten Villumsen.

Contributors All authors contributed significantly to the design of this scoping review and lived up to the requirements of the International Committee of Medical Journal Editors (ICMJE). Author contribution varied in the different phases of the project with TSP, SB and MV being involved in all phases. TSP, SB, MH, PH and MV contributed to the conception, design and planning of the scoping review. TSP, SB, MV, PB-L, VD-G, FL, NG and SWC contributed to the data collection, and TSP, SB and MV were responsible for data analysis. The interpretation of data and writing of manuscript were led by TSP, SB and MV with support from MH, PH, PB-L, VD-G, $\mathrm{FL}, \mathrm{NG}$ and SWC. No patients or other members of the public were involved in this work.

Funding This study was funded by Erasmus+ Program (agreement no. 20182381/001-001, project no. 600920-EPP-1-2018-1-ES-EPPKA2-KA).

Disclaimer The funding body had no influence on the outcome or interpretation of findings.

Competing interests None declared.

Patient consent for publication Not required.

Provenance and peer review Not commissioned; externally peer reviewed.

Data availability statement Data can be made available on reasonable request to the authors.

Open access This is an open access article distributed in accordance with the Creative Commons Attribution Non Commercial (CC BY-NC 4.0) license, which permits others to distribute, remix, adapt, build upon this work non-commercially, and license their derivative works on different terms, provided the original work is properly cited, appropriate credit is given, any changes made indicated, and the use is non-commercial. See: http://creativecommons.org/licenses/by-nc/4.0/.

\section{ORCID iDs}

Thorvaldur Skuli Palsson http://orcid.org/0000-0002-4418-0133

Pablo Herrero http://orcid.org/0000-0002-9201-0120

\section{REFERENCES}

1 Dagenais S, Caro J, Haldeman S. A systematic review of low back pain cost of illness studies in the United States and internationally. Spine J 2008;8:8-20.

2 Hartvigsen J, Hancock MJ, Kongsted A, et al. What low back pain is and why we need to pay attention. Lancet 2018;391:2356-67.

3 McDonald M, DiBonaventura MdaCosta, Ullman S. Musculoskeletal pain in the workforce: the effects of back, arthritis, and fibromyalgia pain on quality of life and work productivity. J Occup Environ Med 2011;53:765-70.

4 Vlaeyen JWS, Maher CG, Wiech K, et al. Low back pain. Nat Rev Dis Primers 2018;4:52

5 VCW H, Urquhart DM, Kelsall HL, et al. Ergonomic interventions for preventing work-related musculoskeletal disorders of the upper limb and neck among office workers. Cochrane Database Syst Rev 2018;10.

6 Verbeek JH, Martimo K-P, Kuijer PPFM, et al. Proper manual handling techniques to prevent low back pain, a Cochrane systematic review. Work 2012;41:2299-301.

7 Jensen JN, Karpatschof B, Labriola M, et al. Do fear-avoidance beliefs play a role on the association between low back pain and sickness absence? A prospective cohort study among female health care workers. J Occup Environ Med 2010;52:85-90.

8 Rashid M, Kristofferzon M-L, Nilsson A, et al. Factors associated with return to work among people on work absence due to longterm neck or back pain: a narrative systematic review. BMJ Open 2017;7:e014939.

9 Nicholas MK. Importance of being collaborative for return to work with back pain. Pain 2018;159:1431-2.

10 Sennehed CP, Holmberg S, Axén I, et al. Early workplace dialogue in physiotherapy practice improved work ability at 1-year followup-WorkUp, a randomised controlled trial in primary care. Pain 2018;159:1456-64.

11 Jay K, Brandt M, Hansen K, et al. Effect of individually tailored biopsychosocial workplace interventions on chronic musculoskeletal pain and stress among laboratory technicians: randomized controlled trial. Pain Physician 2015;18:459-71.
12 Brendbekken R, Eriksen HR, Grasdal A, et al. Return to work in patients with chronic musculoskeletal pain: multidisciplinary intervention versus brief intervention: a randomized clinical trial. $J$ Occup Rehabil 2017;27:82-91.

13 Curnock E, Leyland AH, Popham F. The impact on health of employment and welfare transitions for those receiving out-of-work disability benefits in the UK. Soc Sci Med 2016;162:1-10.

14 Rasmussen CDN, Holtermann A, Jørgensen MB, et al. A multifaceted workplace intervention targeting low back pain was effective for physical work demands and maladaptive pain behaviours, but not for work ability and sickness absence: stepped wedge cluster randomised trial. Scand J Public Health 2016;44:560-70.

15 Sultan-Taïeb H, Parent-Lamarche A, Gaillard A, et al. Economic evaluations of ergonomic interventions preventing work-related musculoskeletal disorders: a systematic review of organizationallevel interventions. BMC Public Health 2017;17:935

16 Gardner T, Refshauge K, McAuley J, et al. Combined education and patient-led goal setting intervention reduced chronic low back pain disability and intensity at 12 months: a randomised controlled trial. $\mathrm{Br}$ J Sports Med 2019;53:1424-31.

17 Tegner H, Frederiksen P, Esbensen BA, et al. Neurophysiological pain-education for patients with chronic low back pain - a systematic review and meta-analysis. Clin J Pain 2018;34:1-86.

18 Traeger AC, Lee H, Hübscher M, et al. Effect of intensive patient education vs placebo patient education on outcomes in patients with acute low back pain. JAMA Neurol 2019;76:161-9.

19 Frederiksen P, Indahl A, Andersen LL, et al. Can group-based reassuring information alter low back pain behavior? A clusterrandomized controlled trial. PLoS One 2017;12:e0172003.

20 Ree E, Lie SA, Eriksen HR, et al. Reduction in sick leave by a workplace educational low back pain intervention: a cluster randomized controlled trial. Scand J Public Health 2016;44:571-9.

21 Tricco AC, Lillie E, Zarin W, et al. PRISMA extension for scoping reviews (PRISMA-ScR): checklist and explanation. Ann Intern Med 2018;169:467-73.

22 Moher D, Liberati A, Tetzlaff J, et al. Preferred reporting items for systematic reviews and meta-analyses: the PRISMA statement. PLoS Med 2009;6:e1000097.

23 Parent-Thirion A, Biletta I, Cabrita J, et al. Eurofound: sixth European working conditions survey-overview report (2017 update). Luxembourg: Publications Office of the European Union, 2017.

24 Arksey H, O'Malley L. Scoping studies: towards a methodological framework. Int J Soc Res Methodol 2005;8:19-32.

25 Aghilinejad M, Azar NS, Ghasemi MS, et al. An ergonomic intervention to reduce musculoskeletal discomfort among semiconductor assembly workers. Work 2016;54:445-50.

26 Blangsted AK, Søgaard K, Hansen EA, et al. One-year randomized controlled trial with different physical-activity programs to reduce musculoskeletal symptoms in the neck and shoulders among office workers. Scand J Work Environ Health 2008;34:55-65.

27 Frost P, Haahr JP, Andersen JH. Reduction of pain-related disability in working populations: a randomized intervention study of the effects of an educational booklet addressing psychosocial risk factors and screening workplaces for physical health hazards. Spine 2007;32:1949-54.

28 Gram B, Holtermann A, Bültmann U, et al. Does an exercise intervention improving aerobic capacity among construction workers also improve musculoskeletal pain, work ability, productivity, perceived physical exertion, and sick leave?: a randomized controlled trial. J Occup Environ Med 2012;54:1520-6.

29 Hazard RG, Reid S, Haugh LD, et al. A controlled trial of an educational pamphlet to prevent disability after occupational low back injury. Spine 2000;25:1419-23.

30 Hutting N, Staal JB, Engels JA, et al. Effect evaluation of a selfmanagement programme for employees with complaints of the arm, neck or shoulder: a randomised controlled trial. Occup Environ Med 2015;72:852-61.

31 Korshøj M, Birk Jørgensen M, Lidegaard M, et al. Decrease in musculoskeletal pain after 4 and 12 months of an aerobic exercise intervention: a worksite RCT among cleaners. Scand J Public Health 2018;46:846-53.

32 Rantonen J, Vehtari A, Karppinen J, et al. Face-to-face information combined with a booklet versus a booklet alone for treatment of mild low-back pain: a randomized controlled trial. Scand J Work Environ Health 2014;40:156-66.

33 Rantonen J, Luoto S, Vehtari A, et al. The effectiveness of two active interventions compared to self-care advice in employees with non-acute low back symptoms: a randomised, controlled trial with a 4-year follow-up in the occupational health setting. Occup Environ Med 2012;69:12-20. 
34 Ratzon NZ, Bar-Niv NA, Froom P. The effect of a structured personalized ergonomic intervention program for hospital nurses with reported musculoskeletal pain: an assigned randomized control trial. Work 2016;54:367-77.

35 Caspi CE, Dennerlein JT, Kenwood C, et al. Results of a pilot intervention to improve health and safety for health care workers. $J$ Occup Environ Med 2013;55:1449-55.

36 Farrokhnia T, Rezai M, Vaziri M-H. Investigating the effect of educational intervention on musculoskeletal disorders in dentists. ME-JFM 2018;16:307-13.

37 Feuerstein M, Marshall L, Shaw WS, et al. Multi-component intervention for work-related upper extremity disorders. J Occup Rehabil 2000;10:71-83.

38 Meinert M, König M, Jaschinski W. Web-based office ergonomics intervention on work-related complaints: a field study. Ergonomics 2013;56:1658-68.

39 Slaughter AL, Frith K, O'Keefe L, et al. Promoting best practices for managing acute low back pain in an occupational environment. Workplace Health Saf 2015;63:408-14.

40 de Boer AGEM, Burdorf A, van Duivenbooden C, et al. The effect of individual counselling and education on work ability and disability pension: a prospective intervention study in the construction industry. Occup Environ Med 2007;64:792-7.

41 Rantonen J, Karppinen J, Vehtari A, et al. Cost-effectiveness of providing patients with information on managing mild low-back symptoms in an occupational health setting. BMC Public Health 2016;16:316.

42 Videman T, Rauhala H, Asp S, et al. Patient-handling skill, back injuries, and back pain. An intervention study in nursing. Spine 1989;14:148-56.
43 Wanyonyi N, Frantz J, Saidi H. The effect of a knowledge-based ergonomic intervention amongst administrators at Aga Khan University Hospital, Nairobi. Work 2015;52:843-54.

44 Aghilinejad M, Bahrami-Ahmadi A, Kabir-Mokamelkhah E, et al. The effect of three ergonomics training programs on the prevalence of low-back pain among workers of an Iranian automobile factory: a randomized clinical trial. Int J Occup Environ Med 2014;5:65-71.

45 Hutting N, Detaille SI, Heerkens YF, et al. Experiences of participants in a self-management program for employees with complaints of the arm, neck or shoulder (CANS): a mixed methods study. J Occup Rehabil 2017;27:35-48.

46 Doda D, Rothmore P, Pisaniello D, et al. Relative benefit of a stage of change approach for the prevention of musculoskeletal pain and discomfort: a cluster randomised trial. Occup Environ Med 2015;72:784-91.

47 Hutting N, Detaille SI, Engels JA, et al. Development of a selfmanagement program for employees with complaints of the arm, neck, and/or shoulder: an intervention mapping approach. $J$ Multidiscip Healthc 2015;8:307-20.

48 Shorthouse FM, Roffi V, Tack C. Effectiveness of educational materials to prevent occupational low back pain. Occup Med 2016;66:623-9.

49 lo M. Evidence-based medicine and the changing nature of health care: 2007 IOM Annual Meeting Summary. In: McClellan MB, McGinnis JM, Nabel EG, eds. Washington, DC: The National Academies Press, 2008: 202.

50 McGowan J, Sampson M, Salzwedel DM, et al. PRESS Peer Review of Electronic Search Strategies: 2015 Guideline Statement. J Clin Epidemiol 2016;75:40-6. 